\title{
The best modern practices to reduce surgical complications after total hip and knee replacement
}

\author{
Amal Elramli ${ }^{1, *}$, Abdelhaq Elmansori ${ }^{2}$ \\ 1 School of Medicine, University of Glasgow, Glasgow, UK \\ 2 Faculty of Medicine, University of Benghazi, Benghazi, Libya \\ *Correspondence to: Amal Elramli, Ph.D. candidate, a.elramli.1@research.gla.ac.uk. \\ orcid: 0000-0001-5919-1292
}

\section{Abstract}

Although there is the use of pharmacological prophylaxis to prevent venous thromboembolic diseases after total hip or knee replacement, venous thromboembolism is considered one of the main and serious complications. Moreover, the incidence of deep venous thrombosis among the patients who have total hip or total knee replacements is still high. The use of regional anaesthesia in arthroplasty has been increasing recently. In addition to its effects in elimination pain, regional anaesthesia may help to reduce the incidence of postoperative thromboembolism. Given this, this paper aims to highlight the role of regional anaesthesia to improve outcomes of hip and knee arthroplasty.

Key words: total hip and knee replacement; deep venous thrombosis; arthroplasty; regional anaesthesia

doi: $10.4103 / 2468-5674.183008$

How to cite this article: Elramli A, Elmansori A (2016) The best modern practices to reduce surgical complications after total hip and knee replacement. Clin Transl Orthop 1(2):85-87.

\section{INTRODUCTION}

Most total hip or knee replacements are performed for advanced osteoarthritis. The other common causes are rheumatoid arthritis and avascular necrosis or fractures such as proximal femoral fracture (Singh, 2011; Lenza et al., 2013).

A systematic review done by Singh (2011) revealed a growing prevalence of total hip replacement and total knee replacement over the last decade worldwide. In USA, the prevalence of total knee replacement was increased from 5.5 to 8.7 per 1,000 populations in $2000-2006$ and that of total hip replacement from $9.5 / 100,000$ to $15.2 / 100,000$ in 1990-2002 (Kurtz et al., 2005). The risk of death after total hip or knee replacement is increasing, and by identifying the modifiable factors, it may help to minimise the mortality rate (Berstock et al., 2014). Therefore, postoperative complications and the best practices to reduce complications are the most important issues of concern.

\section{POST-TOTAL HIP AND KNEE REPLACEMENT COMPLICATIONS}

The main complications of total hip and knee replacement are deep venous thrombosis and pulmonary embolism (Colwell et al., 2010). Also they may lead to dislocation, fracture, infections, and neural deficit (Healy et al., 2013).

Patients undergoing total hip or knee replacement remain at high risk for deep venous thrombosis and pulmonary embolism (Fisher, 2011). A study from Chotanaphuti et al. (2007) was reported that $61 \%$ of patients without thromboprophylaxis were positive for deep venous thrombosis following the total knee replacement. A systematic review showed the incidence of deep venous thrombosis without prophylaxis was up to $42-57 \%$ after total hip replacement and $41-85 \%$ following total knee replacement (Kim et al., 2013).

White et al. (2002) stated 2-4\% of patients diagnosed with deep venous thrombosis. Della et al. (1998) reported that without thromboprophylaxis, the incidence of deep venous thrombosis or pulmonary embolism after total hip and knee replacement exceeded 50\%.

The most common cause of mortality after total hip replacement is pulmonary embolism, with a mortality rate of $3-6 \%$, and the incidence of thromboembolic complications 
is $4 \%$ within 90 days of total hip replacement. Furthermore, it has been reported that total hip replacement has a higher mortality rate than total knee replacement (Berstock et al., 2014).

It has been identified that extended medical thromboprophylaxis plays a role in reducing the risk of thromboembolism (White et al., 2002); however, the benefits of thromboprophylaxis can cause serious complications such as retropulmonary emboliritoneal, intracranial or intraocular bleeding. Also, epistaxis or hematuria may be the sequel (Schulman et al., 2010). Additionally, the use of thromboprophylaxis increases risks of infection, blood transfusion, and unhealed wound (Burnett et al., 2007).

About $40 \%$ of patients undergoing total hip or knee replacement do not receive pharmacological prophylaxis due to an increased risk of bleeding. Although the mechanical methods have been used, they are not effective tools to prevent thromboembolic complications. The benefits and the complications of pharmacological prophylaxis should be considered (Autar, 2011). Despite complications in its use, it advocates an extended use of pharmacological prophylaxis in total hip replacement for 28-35 days and in total knee replacement for 10-14 days, in the absence of any contraindication (Autar, 2011). Therefore, an alternative method that may help to reduce complications and improve the outcomes of total hip or knee replacement is recommended.

\section{THE ROLE OF REGIONAL ANAESTHESIA IN TOTAL HIP AND}

\section{KNEE REPLACEMENT}

The advanced surgical and anaesthesia techniques have improved the outcomes of arthroplasty (Berger et al., 2009). The use of regional anaesthesia, either central neuraxial blockade or peripheral nerve blockade has been increasing over the last decade (Macfarlane et al., 2009).

Regional anaesthesia is considered a safe technique, resulting in extremely rare complications. It may be associated occasionally with minor tenderness and/or bruising at the injection site, while nerve block may be followed by numbness and tingling for a limited time (Macfarlane et al., 2009).

A study (Liu et al., 2014) noted that the postoperative recovery from peripheral nerve blockade in total knee replacement is faster than general anaesthesia $(P<0.001)$. With regional anaesthesia, pre- and post-operative pain elimination reduces the duration of hospital stay, morphine consumption, and nausea and vomiting (Berger et al., 2009; Macfarlane et al., 2009). Berger et al. (2009) stated that 150 patients who had total hip replacement were discharged at day of surgery, while 87 of these patients were able to walk without any assistant devices.
The use of peripheral nerve blockade provides muscle relaxation, vasodilation, and improves limb perfusion. It may also reduce the incidence of bleeding and improve operative outcomes (Macfarlane et al., 2009) compared with central neuraxial blockade (Mauermann et al., 2006). In addition, it can reduce the risk of thromboembolic complications: for deep venous thrombosis, odds ratio $(O R)=0.45,95 \%$ confidence interval $(C I)(0.24$ to 0.84$)$; for pulmonary embolism, $O R=0.46,95 \% C I$ ( 0.29 to 0.80 ) (Hu et al., 2009). No risk of hematoma or bleeding is noted in combination of peripheral nerve blocks and thromboprophylaxis and/or aspirin, and it can be performed safely (Chelly and Schilling, 2008).

No difference is demonstrated in the incidence of deep venous thrombosis or pulmonary embolism between general anaesthesia and regional anaesthesia. However, intraoperative blood loss and blood transfusion are reduced among patients undergoing regional anaesthesia compared with general anaesthesia (Macfarlane et al., 2009).

There is compelling evidence to support the use of regional anaesthesia over that of general anaesthesia. Regional anaesthesia reduces the duration of surgery, postoperative vomiting, thrombotic complications and blood transfusion. In addition, the use of peripheral nerve blockade to minimise the use of opioids and their consequent side effects may be beneficial (Hu et al., 2009). As other methods, regional anaesthesia has both benefits and adverse effects; however complications arising from their use are less likely to be severe. Recent evidence proves the trend towards the increased use of regional anaesthesia for total hip and knee replacement, with or without general anaesthesia; however, its role in reducing the incidence of thromboembolic complications is still unclear (Hu et al., 2009). There is still insufficient evidence of randomized controlled trials regarding the influence of regional anaesthesia in deep venous thrombosis or pulmonary embolism (Dauphin et al., 1997; Macfarlane et al., 2009).

\section{Conclusion}

Thromboprophylaxis plays an important role to decrease the incidence of deep venous thrombosis and pulmonary embolism post arthroplasy. However, complications of its use are often serious and life-threatening. Based on aforementioned evidence, regional anaesthesia has many advantages and can be used safely in patients undergoing arthroplasty. Its role on the incidence of deep venous thrombosis and pulmonary embolism in arthroplasty is still unclear and further randomized controlled trials are recommended to examine the influence of regional anaesthesia in total hip and knee replacement. 


\section{Conflicts of interest}

The authors declare no competing financial interests. Author contributions

Both authors collected data, wrote the paper, and approved the final version of this paper for publication.

Plagiarism check

This paper was screened twice using CrossCheck to verify originality before publication.

Peer review

This paper was double-blinded and stringently reviewed by international expert reviewers.

\section{References}

Autar R (2011) Evidence based venous thromboprophylaxis in patients undergoing total hip replacement, total knee replacement (TKR) and hip fracture surgery (HFS). Int J Ortho Trama Nur 15:145-154.

Berstock JR, Beswick AD, Lenguerrand E, Whitehouse MR, Blom AW (2014) Mortality after total hip replacement surgery: a systematic review. Bone Joint Res 3:175-182.

Burnett RS, Clohisy JC, Wright RW, McDonald DJ, Shively RA, Givens SA, Barrack RL (2007) Failure of the American College of Chest Physicians-1A protocol for lovenox in clinical outcomes for thromboembolic prophylaxis. J Arthroplasty 22:317-324.

Chelly JE, Schilling D (2008) Thromboprophylaxis and peripheral nerve blocks in patients undergoing joint arthroplasty. J Arthroplasty 23:350-354.

Chotanaphuti T, Ongnamthip P, Silpipat S, Foojareonyos T, Roschan S, Reumthantong A (2007) The prevalence of thrombophilia and venous thromboembolism in total knee arthroplasty. J Med Assoc Thai 90:1342-1347.

Colwell CW Jr, Froimson MI, Mont MA, Ritter MA, Trousdale RT, Buehler KC, Spitzer A, Donaldson TK, Padgett DE (2010) Thrombosis prevention after total hip arthroplasty. J Bone Joint Surg Am 92:527-535.

Dauphin A, Raymer KE, Stanton EB, Fuller HD (1997) Comparison of general anesthesia with and without lumbar epidural for total hip arthroplasty: effects of epidural block on hip arthroplasty. J Clin Anesth 9:200-203.

Della Valle Craig J, Steiger David J, Di Cesare Paul E (1998) Thromboembolism after hip and knee arthroplasty: diagnosis and treatment. J Am Acad Orthop Surg 6:327-336.
Fisher WD (2011) Impact of venous thromboembolism on clinical management and therapy after hip and knee arthroplasty. Can J Surg 54:344-351

Healy WL, Della Valle CJ, Iorio R, Berend KR, Cushner FD, Dalury DF, Lonner JH (2013) Complications of total knee arthroplasty: standardized list and definitions of the Knee Society. Clin Orthop Relat Res 471:215-220.

Hu S, Zhang ZY, Hua YQ, Li J, Cai ZD (2009) A comparison of regional and general anaesthesia for total replacement of the hip or knee: a meta-analysis. J Bone Joint Surg Br 91:935-942.

Kim KI, Kang DG, Khurana SS, Lee SH, Cho YJ, Bae DK (2013) Thromboprophylaxis for deep vein thrombosis and pulmonary embolism after total joint arthroplasty in a low incidence population. Knee Surg Relat Res 25:43-53.

Kurtz S, Mowat F, Ong K, Chan N, Lau E, Halpern M (2005) Prevalence of primary and revision total hip and knee arthroplasty in the United States from 1990 through 2002. J Bone Joint Surg Am 87:1487-1497.

Lenza M, Ferraz Sde B, Viola DC, Garcia Filho RJ, Cendoroglo Neto M, Ferretti M (2013) Epidemiology of total hip and knee replacement: a cross-sectional study. Einstein (Sao Paulo) 11:197202.

Liu J, Yuan W, Wang X, Royse CF, Gong M, Zhao Y, Zhang H (2014) Peripheral nerve blocks versus general anesthesia for total knee replacement in elderly patients on the postoperative quality of recovery. Clin Interv Aging 9:341-350

Macfarlane AJ, Prasad GA, Chan VW, Brull R (2009) Does regional anaesthesia improve outcome after total hip arthroplasty? A systematic review. Br J Anaesth 103:335-345.

Mauermann WJ, Shilling AM, Zuo Z (2006) A comparison of neuraxial block versus general anesthesia for elective total hip replacement: a meta-analysis. Anesth Analg 103:1018-1025.

Schulman S, Angerås U, Bergqvist D, Eriksson B, Lassen MR, Fisher W (2010) Subcommittee on control of anticoagulation of the scientific and standardization committee of the international society on thrombosis and haemostasis. Definition of major bleeding in clinical investigations of antihemostatic medicinal products in surgical patients. J Thromb Haemost 8:202-204.

Singh JA (2011) Epidemiology of knee and hip arthroplasty: a systematic review. Open Orthop J 16:80-85.

White RH, Henderson MC (2002) Risk factors for venous thromboembolism after total hip and knee replacement surgery. Curr Opin Pulm Med 8:365-371. 